\title{
Use of hormone replacement therapy in 1976-89 by 45-64 year old Finnish women
}

\author{
Päivi Topo, Timo Klaukka, Elina Hemminki, Antti Uutela
}

\begin{abstract}
Study objective-The aim was to describe changes in the use of hormone replacement therapy (HRT) in Finland during the period 1976-1989.

Design-The study involved four separate cross sectional population surveys in the years 1976, 1978-1980, 1987, and 1989. Three of them involved interviews and one a questionnaire. Sales figures of hormones in 1981-1989 were used.

Participants-Participants were national samples of non-institutionalized Finnish women 45-64 years of age. Participation rates ranged from $85 \%$ to $96 \%$.

Measurements and main resultsCurrent reported hormone use in the surveys of 1976, 1978-1980, and 1987 was assessed, together with reported hormone use in the last month in the 1989 survey. During the study period the proportion of HRT users increased fivefold. In 1989, $20 \%$ of women reported current use of HRT, and the highest rate of use was found among 50-54 year old women in the Helsinki area. In 1976, users were mainly women around the age of menopause, those living in the capital area, and those having a rather high level of education. By 1989 use had spread to postmenopausal women, those in rural areas, and those with less education.

Conclusions-Use of HRT has increased in Finland. It is difficult to evaluate whether the level of current use is too high, optimal, or too low, because recommendations are contradictory and the long term effects of HRT are unkown.
\end{abstract}

Hormone replacement therapy (HRT) during the menopause and in the postmenopausal period has been available for more than 40 years. ${ }^{1}$ At first only oestrogens were used in many countries. Later, when the relation between oestrogen therapy and endometrial cancer was discovered oestrogen-progestin combinations became more common. Researchers have been interested in HRT because of its popularity, its uncertain indications, and the lack of information about side effects from long term use. ${ }^{2-8}$ The identification of osteoporosis as a major public health problem has been a further stimulus for research.

Despite the popularity of HRT there is little information about HRT users. All previous data on the changes in the use of HRT are based on numbers of prescriptions or sales. In this article we report how HRT usage has changed in Finland in different age and socioeconomic groups as well as regionally. Our data derive from three nationwide interview studies and a mail questionnaire survey. In addition we have made use of sales figures for these medicines.

\section{Methods}

Strictly speaking, the menopause is defined as the final menstrual bleeding. In this study menopause means the symptomatic period around the last menstrual bleeding. Because our data do not permit us to define the exact time of the menopause of the women studied, we shall call all women of at least 55 years of age postmenopausal.

The study subjects come from four population surveys conducted in Finland in 1976, 1978-1980, 1987, and 1989.

\section{SURVEY 1}

The material of the 1976 study was derived from a nationwide health interview survey. The data were collected through household interviews carried out by public health nurses from local health centres. The sample (16413 adults and 4605 children) represented the total noninstitutionalized population of the country; the participation rate was $91^{\circ} .^{9}$

\section{SURVEY 2}

The same methodology as above was used in the 1987 study. The sample size was 13138 adults and 3131 children, and the participation rate was $85 \%{ }^{10}$

\section{SURVEY 3}

The Mini-Finland Health Survey in 1978-1980 in 40 areas contained an interview, which was methodologically identical with those in the previous two health surveys. The study population consisted of 7612 people, who were at least 30 years old, and the participation rate was $96^{\circ}{ }^{11}$

\section{SURVEY 4}

In 1989 a random sample $(n=2000)$ of all Finnish women 45-64 years of age was drawn from the Finnish Population Register, and a questionnaire on the menopause and the use of health services and drugs was mailed to them. The answers were anonymous, and those who responded were identified by a name tag which they returned in a separate envelope. The response rate after two reminders was $86^{\circ} \%$.

The question concerning use of medicines in the studies of $1976,1978-1980$, and 1987 was the following: "What prescription drugs do you use at the moment?" The names of the drugs were 
copied from the prescription forms or containers for all drugs they were currently using. In the 1989 study, the use of HRT was determined by the question: "Have you used hormones (oestrogens or oestrogen-progestin combinations) during the last month (30 days)? State the name of the drug."

The medicines classified in the Finnish drug compendium, Pharmaca Fennica, for menopausal and postmenopausal hormonal treatment, and containing either oestrogens alone, oestrogens combined to progestins, or oestrogens combined to other drugs, were included. Progestin taken alone was not included. Pharmaca Fennica classifies drugs in a way similar to the ACT classification used by the Nordic Council on Medicines.

In each survey the level of general education included three alternatives: primary school (7-8 years), junior secondary school (9-10 years), and senior secondary school (12-13 years). In 1976 and 1987 respondents' place of residence was classfied as the Helsinki metropolitan area (including Helsinki and three neighbouring towns), other towns, and rural areas. In 1989 the name of the municipality was not asked, and the Helsinki metropolitan area was defined as all the towns located in the county, which made the category much larger than in the other studies.

The sales figures for hormones mainly used for HRT-GO3F, GO3C and GO3E in the official Nordic ATC drug classification-were obtained for the years 1981-1986 from a previously published article ${ }^{12}$ and in 1987-1989 from Finnish Statistics on Medicines. ${ }^{13-15}$ The sales figures were given as defined daily doses (DDD).

Statistical significance of differences in distributions were tested by $\chi^{2}$ test. Differences were tested between the study years and between the various subgroups within a year separately.

\section{Results}

During the first 11 years studied, HRT usage among 45-64 year old women increased threefold (from $4 \%$ to $12 \%$ ) (table I). In 1989 the number of current HRT users increased further nearly twofold. While this increase occurred in every age group, most interesting is the rapid increase in HRT use among 55-64 year old postmenopausal women. All the differences between the years were statistically significant $(p<0.001)$. For all periods, use of HRT was most common in the age group 50-54 years. The variation in the treatment length was notable: $32 \%$ of the users had used it, this far, for at most a year, $43 \%$ between 13 months and 5 years, and $25 \%$ more than 5 years. As expected, short treatments were more common among young women and long treatments among

Table I Proportion of women 45-64 years old using hormone replacement therapy 1976-1989

\begin{tabular}{|c|c|c|c|c|}
\hline \multirow{3}{*}{$\begin{array}{l}\text { Age (years) } \\
45-49 \\
50-54 \\
55-59 \\
60-64\end{array}$} & \multicolumn{4}{|l|}{ Year } \\
\hline & $\begin{array}{l}1976 \\
\%(n)\end{array}$ & $\begin{array}{l}1978-1980 \\
\%(n)\end{array}$ & $\begin{array}{l}1987 \\
{ }_{0}(n)\end{array}$ & $\begin{array}{l}1989 \\
\% \%(n)\end{array}$ \\
\hline & $\begin{array}{ll}5 & (773) \\
7 & (719) \\
3 & (598) \\
1 & (497)\end{array}$ & $\begin{aligned} 6 & (381) \\
13 & (440) \\
8 & (422) \\
3 & (322)\end{aligned}$ & $\begin{aligned} 10 & (623) \\
22 & (470) \\
10 & (466) \\
5 & (449)\end{aligned}$ & $\begin{array}{ll}10 & (319) \\
28 & (436) \\
24 & (395) \\
14 & (493)\end{array}$ \\
\hline Total & $4(2687)$ & $8(1565)$ & $12(2008)$ & $19(1644)$ \\
\hline
\end{tabular}

older women: $37 \%$ of the 60 years or older users has used HRT more than 5 years. Furthermore sales figures show an increase in the use of oestrogen, oestrogen combined with progestin, and oestrogen combined with other drugs in the period 1981-1989. The increase has been more rapid after 1986 (fig 1).

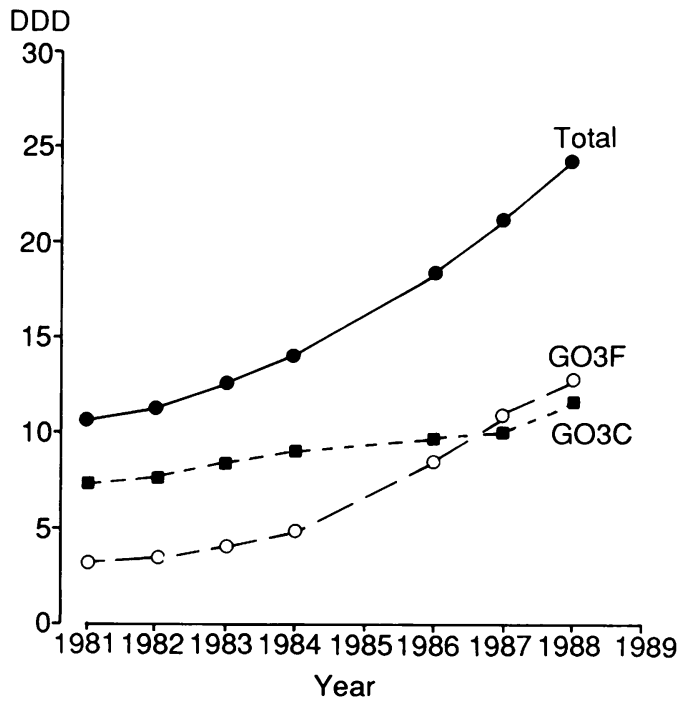

Figure 1 Sales of hormones used in menopause and postmenopause in Finland 1981-1989, in defined daily doses $(D D D), G O 3 C=$ oestrogens and their combinations (other than those with progestins); $G O 3 F=$ combinations of oestrogens and progestins; Total $=G O 3 C+G O 3 F+$

$G O 3 E$ (oestrogens and androgens).

Table II Use of hormone replacement therapy by age and area of residence, 1976, 1987, and 1989

\begin{tabular}{|c|c|c|c|c|}
\hline \multirow{4}{*}{$\begin{array}{l}\begin{array}{l}\text { Age } \\
\text { (years) }\end{array} \\
45-49\end{array}$} & \multirow{5}{*}{$\begin{array}{l}\text { Area of } \\
\text { residence }\end{array}$} & \multicolumn{3}{|l|}{ Year } \\
\hline & & $\begin{array}{l}1976 \\
o_{0}(n)\end{array}$ & $\begin{array}{l}1987 \\
{ }_{0}(n)\end{array}$ & $\begin{array}{l}1989 \\
{ }_{0}(n)\end{array}$ \\
\hline & & 7 (112) & (92) & $12(64)$ \\
\hline & & 3 (324) & $14(305)$ & $11(140)$ \\
\hline & & 1 (337) & $5(226)$ & $8(115)$ \\
\hline \multirow[t]{3}{*}{$50-54$} & Helsinki & $12 \quad(81)$ & $29 \quad(73)$ & $40 \quad(77)$ \\
\hline & Other towns & $10(307)$ & $26 \quad(215)$ & $26(180)$ \\
\hline & Rural areas & $5(331)$ & $14(182)$ & 25 (173) \\
\hline \multirow[t]{3}{*}{$55-59$} & Helsinki & 2 (77) & $22 \quad(64)$ & $37(71)$ \\
\hline & Other towns & $5(231)$ & 9 (211) & $21(164)$ \\
\hline & Rural areas & $1(290)$ & 8 (191) & $20(154)$ \\
\hline \multirow[t]{3}{*}{$60-64$} & Helsinki & $3 \quad 64)$ & $17 \quad(47)$ & $29(65)$ \\
\hline & Other towns & $0 \quad(186)$ & 4 (206) & $14(215)$ \\
\hline & Rural areas & $0 \quad(247)$ & 3 (196) & $9(205)$ \\
\hline \multirow[t]{3}{*}{ Total } & Helsinki & $6(396)$ & 17 (322) & $30(282)$ \\
\hline & Other towns & $4(1225)$ & $12(1104)$ & $18(722)$ \\
\hline & Rural areas & $2(1389)$ & $7(958)$ & $15(674)$ \\
\hline
\end{tabular}

(Numbers in parentheses give denominators)

HRT use was more common in towns than in rural areas during the whole study period (table II) and most common in the capital area. The subgroup with the highest level of use was 50-54 year old women living in the Helsinki area. Increase in use from 1976 to 1987 was, however, greatest in the countryside (a $7 \cdot 5$-fold increase) and the urban-rural difference became smaller in 1989. All these differences between the areas of residence were statistically significant ( $p$ at least $<0.01$ ).

Use of HRT was infrequent in the oldest age group (60-64 years) in 1986, with none of the rural women 60 to 64 years old using HRT. With time, HRT use also appeared in the oldest age group (table II). 
The more education women had the more likely they were to use HRT (fig 2). (The differences between the educational groups were statistically significant, with $p$ at least $<0.01$.) The educational level of the general population had risen between 1976 and 1989 , so that younger age groups were better educated in 1989 than in 1976. For this reason we combined age with education in studying use of HRT. A relationship between education and HRT use was systematic only among women of 55 years or over.

\section{Discussion}

Both population surveys and sales statistics produced similar information about a general increase in HRT usage in Finland. The varying data collection method in the 1989 survey as compared to the previous surveys may have influenced the exact estimate of the level of use, but is unlikely to bias the trend. This development in Finland has differed from that in the United States, where use of HRT declined in the mid 1970s and increased again in the 1980s. ${ }^{3-41718}$ Comparing sales figures, HRT has been used less in Finland than in Denmark and Sweden but more than in Norway. ${ }^{1920}$

Studies from other countries have also shown the highest level of use to be among 50-54 year old women. ${ }^{81621}$ At 50-54 years, menopausal symptoms are most prominent. Because in our study period, use also became more common for those aged 55 years and over, the indications for HRT are probably becoming more orientated to the prevention of osteoporosis and other health problems of old age.

The fact that better educated women make more use of HRT has also been found in other studies, ${ }^{822}$ though conflicting results have been published. ${ }^{5}$ An important finding of the Finnish studies is that the first people to adopt HRT were highly educated women, its use then spreading to other educational groups. The same rule seems to be applicable to the place of residence, with use spreading from the capital metropolitan area to the rural areas. This is similar to certain other health related movements-for example the now widespread use of vitamin supplements in Finland followed the same pattern. ${ }^{23}$

Reasons for this increased popularity of HRT may be that there are now more gynaecological services available, doctors' attitudes towards HRT may have changed, and women are better informed about HRT than before. A great majority of Finnish working age women are in the labour force, which may increase their willingness to use HRT to minimise menopausal discomforts.

One important question concerns the optimal level of HRT use. In regard to the prevention of osteoporosis a Finnish group of experts established by the National Board of Health, concluded that all postmenopausal women without contraindications should be prescribed HRT to prevent osteoporosis. ${ }^{24} \mathrm{By}$ this criterion, HRT use in Finland is still too low. The Swedish National Board of Health and Welfare ${ }^{25}$ took a more cautious stand, recommending HRT for prevention of osteoporosis only for women with prolonged periods of amenorrhoea or early menopause. The number of such women is

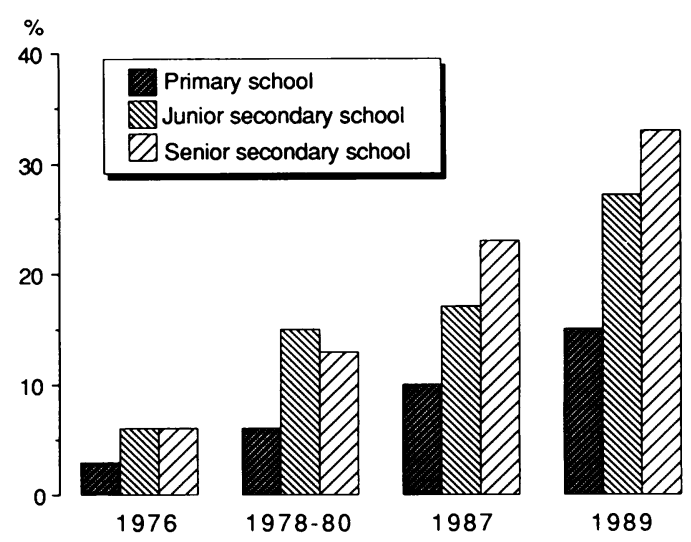

Figure 2 Use of hormone replacement therapy by education, 1976, 1978-80, 1987, and 1989.

probably smaller than the current numbers of users of HRT in Finland. A consensus development conference, sponsored by the European Foundation for Osteoporosis and Bone Disease, recommended HRT for osteoporosis prophylaxis only for women identified as being at risk. $^{26}$ Because it is expensive and technically difficult to establish that a woman is at risk of contracting postmenopausal osteoporosis, this approach may not be feasible in practice.

An additional fact in this controversial field is that the long term benefits and dangers of HRT are not known. For example there are contradictory results on the association between HRT and breast cancer ${ }^{22} 2728$ and cardiovascular diseases. ${ }^{27}$ 29-32 Therefore a cautious attitude towards a widespread use of HRT should probably be adopted.

1 Furuhjelm $M$. Oestrogen treatment in the past and the future in cases of oestrogen deficiency. Acta Obstet Gynecol Scand Suppl 1977; 65: 5-10.

2 Berg G, Hammar M, Fåhraeus L et al. Klimakteriella besvär hos 52- och 54-åriga kvinnor i Linköpings kommun (Menopausul problems in 52 year old and 54 year old women in the municipality of Lindköping). Läkartidningen 1985; 82: 2244-6.

3 Kaufert P, McKinlay SM. Estrogen-replacement therapy: the production of medical knowledge and the emergence of policy. In: Lewin E, Olesen V, eds. Women, health and healing. Toward a new perspective. London: Tavistock Publications, 1985: 113-38.

Barrett-Connor E. Postmenopausal estrogens-current prescribing patterns of San Diego gynacologists. West $\mathcal{F}$ Med 1986; 144: 620-1.

5 Kaufert PL. The menopausal transition; the use of estrogen. Can F Public Health Suppl 1986; 77: 86-91.

6 Hemminki E. The use of combined estrogen-progestin replacement therapy. Int $\mathcal{F}$ Tech Assess Health Care 1988; 4: 511-9.

7 Armstrong BK. Oestrogen therapy after the menopauseboon or bane? Med $\mathcal{f}$ Aust 1988; 148: 213-4.

8 Egeland GM, Matthews KA, Kuller LH et al. Characteristics of noncontraceptive hormone users. Prev Med 1988; 17: 403-11.

9 Kalimo E, Nyman K, Klaukka T et al. Need, use and expenses of health services in Finland 1964-1976. Helsinki: Publications of the Social Insurance Institution A:18, 1982. Kalimo E, Häkkinen U, Klaukka T et al. Data about the health security of the Finns. Health status, use of health services, health related lifestyle and health care costs to families by population group in 1987. Helsinki: Publications
of the Social Insurance Institution M:67, 1989 .

11 Aromaa A, Heliövaara M, Impivaara O et al. Aims, method and study population. Part 1 . In: Aromaa A, Heliövaara M, Impivaara $\mathrm{O}$ et al, eds. The execution of the Mini-Finland health survey. Helsinki: Publications of the Social Insurance Institution ML:88, 1989.

12 Hemminki E, Makkonen K. Progestiinit ja vaihdevuosien hoito-esimerkki lääketieteellisen teknologian arvioinnin ongelmista (Progestins in the treatment of the menopause: an example of evaluation of medical technology). Sosiaalilääketiet Aikakauslehti 1988; 1: 69-80.

13 The Finnish Committee on Drug Information and Statistics. Finnish statistics on medicines 1987. Helsinki: National Board of Health and The Social Insurance Institution, 1988. 
14 The Finnish Committee on Drug Information and Statistics. Finnish statistics on medicines 1988. Helsink National Board of Health and The Social Insurance Institution, 1989.

15 The Finnish Committee on Drug Information and Statistics. Finnish statistics on medicines 1989. Helsinki: National Board of Health and The Social Insurance Institution, 1990.

16 Rosenberg L, Shapiro S, Kaufman DW et al. Patterns and derterminants of conjugated estrogen use. Am $\mathcal{f}$ Epidemiol derterminants of con

17 Hemminki E, Kennedy DL, Baum C, McKinlay SM Prescribing of noncontraceptive estrogens and progestin in the United States, 1974-1986. Am F Public Health 1988, 78: $1479-81$

18 Kennedy DL, Baum C, Forbes MB. Non contraceptive estrogens and progestins: use patterns over time. Obste Gynecol 1985; 65: 441-6.

19 Nordic Council on Medicines. Nordic statistics on medicine 1984-1986. Uppsala: Nordic Council, 1988

20 Norwegian Medical Depot. The drug consumption in Norway. Oslo: Norwegian Medical Department, 1984, 1986.

21 Appleyard M, ed. The Copenhagen City Heart Study Osterbroundersögelsen. Scand 7 Soc Med Suppl 1986; 41

22 Standeven M, Criqui MH, Klauber MR et al. Correlates of change in postmenopausal estrogen use in population based study. Am 7 Epidemiol 1986; 124: 268-74.

23 Klaukka T, Riska E, Kimmel U-M. Use of vitamin supplements in Finland. Eur $\mathcal{f}$ Clin Pharmacol 1985; 29: supplem.
24 National Board of Health. Osteoporoosityöryhmän mietintö (Report of a working group concerning osteoporis, Nationa Board of Health) Helsinki: Lääkintöhallituksen työryhmien mietintöjä 5, 1987.

25 Drug Information Committee. Osteoporosis: pharmacological treatment and prophylaxis (Workshop). pharmacological treatment and prophylaxis (Workshop). 26 Consensus development conference. Prophylaxis and treatment of osteoporosis. Conference report. BMF 1987; 295: 914-5.

27 Henderson BE, Ross RK, Lobo RA et al. Re-evaluating the role of progestogen therapy after the menopause. Fertil Steril Suppl 1988; 49: 9-15.

28 Wingo PA, Layde PM, Lee NC et al. The risk of breast cancer in postmenopausal women who have used estrogen replacement therapy. $\mathcal{f} A M A$ 1987; 257: 209-15.

29 Barrett-Connor E, Brown V, Turner J et al. Heart disease risk factors and hormone use in postmenopausal women. fAMA 1979; 241: 2167-9.

30 Bush T, Barrett-Connor E. Noncontraceptive estrogen use and cardiovascular disease. Epidemiol Rev 1985; 7: 80-104.

31 Stampfer MJ, Willett WC, Colditz GA et al. A prospective study of postmenopausal estrogen therapy and coronary heart disease. $N$ Engl $\mathcal{F}$ Med 1985; 313: 1044-9.

32 Wilson PWF, Garrison RJ, Castelli P. Postmenopausal estrogen use, cigarette smoking, and cardiovascular morbidity in women over $50 . N$ Engl f Med 1985; 313 : morbidity. 